\title{
Sequential decisions in the Diamond-Dybvig banking model
}

\author{
Markus Kinateder, \\ Universidad de Navarra* \\ Hubert János Kiss, \\ Eötvös Loránd University and MTA KRTK ${ }^{\dagger}$
}

15 September 2014

\begin{abstract}
We study the Diamond-Dybvig model of financial intermediation (Diamond, D., Dybvig, P., 1983. Bank runs, deposit insurance and liquidity. Journal of Political Economy 91 (3), 401-419.) under the assumption that depositors have information about previous decisions. Depositors decide sequentially whether to withdraw their funds or continue holding them in the bank. If depositors observe the history of all previous decisions, we show that there are no bank runs in equilibrium independently of whether the realized type vector selected by nature is of perfect or imperfect information. Our result is robust to several extensions.
\end{abstract}

*Departamento de Economía, Edificio de Amigos, Universidad de Navarra, 31009 Pamplona, Spain. E-mail: mkinateder@unav.es. Phone: +34-948-425 600 ext. 802787.

${ }^{\dagger}$ Corresponding author; Department of Economics, Eötvös Loránd University, 1117 Pázmány sétány 1/a, Budapest, Hungary. E-mail: hubert.kiss@tatk.elte.hu. Phone: +3630-4938062. Kiss is also a research fellow in the "Momentum" (LD-004/2010) Game Theory Research Group at MTA KRTK. 
JEL classification numbers: C72, D82, G21

Keywords: Bank Run, Imperfect Information, Perfect Bayesian Equilibrium

\section{Introduction}

It is very inefficient from a social point of view if fundamentally healthy banks are run, so policy should try to prevent its occurrence. Our paper contributes to the literature on bank runs by proposing a theoretical model in which no bank run is the unique equilibrium outcome in a game in which depositors decide sequentially whether to keep the money in the bank or to withdraw it and where it is commonly known that the bank is healthy. Our result requires an extremely high level of available information about previous choices to prevent this kind of bank runs and our theoretical finding is robust to relaxing some of the informational conditions. We convey a clear message to policy makers by highlighting the importance of making depositors' decisions to keep the money in the bank observable to the remaining depositors in the queue which have not yet decided whether to withdraw their money or not. Improving transparency regarding this issue, for example, by publishing the amount of money kept in the bank at increased maturities would potentially decrease the likelihood of bank runs on healthy banks.

While economic conditions and fundamentals are important factors that determine to a large extent if a bank suffers a run (Gorton, 1988; Calomiris and Mason, 2003), several studies point out convincingly that there are banking panics in periods with no economic distress (Ennis, 2003) and that even banks with good fundamentals experience runs (De Graeve and Karas, 2014).

Our model hinges on the assumption that depositors react to other depositors' observed decisions which is supported by empirical studies. Kelly and O Grada (2000), Starr and Yilmaz (2007), and Iyer and Puri (2012) em- 
pirically analyze real-world bank runs and stress that depositors' observed actions affect their peers' decisions. Notably, in all of these cases the banks that suffered the run were fundamentally healthy, bad news about another bank sparked the run. Experimental evidence also suggests that observability plays an important role in the emergence of bank runs (see, for example, Garratt and Keister, 2009; Schotter and Yorulmazer, 2009; Kiss et al., 2012). Moreover, Kiss et al. (2014) study a small-scale environment resembling the Diamond-Dybvig setup in which bank runs are caused by coordination problems. They find that the more depositors can observe previous decisions, the less likely it is that participants withdraw their funds from the bank. More information about previous decisions seems to reduce the likelihood of bank runs. In Garratt and Keister (2009) and Kiss et al. (2014) there were no fundamental problems with the bank and it was common knowledge, so there fundamental problems or negative information about the bank extracted from the behavior of other depositors cannot be behind the runs.

Motivated by the relevance of observability of depositors' decisions even in case of fundamentally healthy banks, we modify the canonical DiamondDybvig model (1983) assuming that depositors perfectly observe the actions taken by those who precede them. We model a sequential-move game with a finite number of depositors who contact the bank in an exogenously given fixed order to communicate whether to leave the money deposited or to withdraw it. We assume that there is aggregate certainty about liquidity types, an assumption used by Diamond and Dybvig (1983) and in recent models, such as Ennis and Keister (2009a). ${ }^{1}$

Converting the original Diamond-Dybvig setup in which depositors decide simultaneously into a sequential-move game yields interesting results. When liquidity types and actions are perfectly observed, then no bank run occurs and the Pareto efficient allocation is the unique equilibrium outcome. Our

\footnotetext{
${ }^{1}$ Diamond and Dybvig (1983) show for the case of stochastic withdrawals that the results found without aggregate uncertainty about liquidity types need not hold.
} 
main contribution is to extend this result to the case when the sequence of liquidity types is of imperfect information, that is, a depositor's liquidity type is her private information.

Under perfect information, our result is obtained by backward induction. Waiting dominates withdrawal for the last patient depositor if enough depositors waited before her. Anticipating this decision, the next to last patient depositor's decision is of the same nature, and by moving backwards, all patient depositors wait.

Under imperfect information, the liquidity type vector is randomly selected by nature and is unobserved by the depositors and the bank. Every depositor, as it is her turn to decide, observes previous decisions and forms beliefs about which type vector was selected, or in other words, whether before her withdrawals were due to impatient depositors only or patient ones as well. Based on her observation, on her belief and on the strategy profile, a depositor determines whether it is optimal for her to withdraw or not. Perfect Bayesian Equilibrium, as defined by Fudenberg and Tirole (1991), imposes a strong rationality criterion on the strategy profile and belief system. This enables us to obtain a unique prediction on depositors' behavior which coincides with the solution under perfect information. On the equilibrium path, patient depositors wait and impatient ones withdraw. We show also that this result is robust to moderate alterations in the model, the only exception being that information about previous decisions should be higly detailed.

Although we cast our model in a banking environment, run-like phenomena occur in other institutions and markets as well in which investors can easily withdraw their funds or cease to roll over their investment. In such settings our analysis applies analogously. For instance, Northern Rock, the English bank was not first run by depositors, but by large creditors who provided short-term funding to the bank and did not renew it. Run-like episodes also occurred in money-market, hedge and pension funds (Baba, McCauley and Ramaswamy, 2009), the repo market (Gorton and Metrick, 2012) and 
even in bank lending (Ivashina and Scharfstein, 2010).

\subsection{Related literature}

In the classic Diamond-Dybvig framework multiple equilibria exist, and the Pareto efficient outcome of no bank run is no unique equilibrium. This suggests that banks are intrinsically fragile and susceptible to self-fulfilling runs. The subsequent literature attempts to identify elements that lead to this kind of fragility. As Ennis and Keister (2010a) point out, it is important to find the ingredients that help understand fragility in models that follow the Diamond-Dybvig tradition as it has relevant consequences for public policy regarding how desirable government-provided safety net elements, like deposit insurance, and other interventions are. Our paper contributes to this understanding by studying the effect of observability that has been mostly disregarded in theoretical papers although the empirical and experimental evidence mentioned above indicates that it matters. The need to introduce observability in models has been suggested by several researchers. For example, Brunnermeier (2001, p.214) claims that “... withdrawals by deposit holders occur sequentially in reality, [whereas] the literature typically models bank runs as a simultaneous move game."

There are two approaches in the literature to study bank runs: one is game theoretic and the other based on mechanism design. Given certain constraints, the mechanism design strand of the literature studies how to optimally assign consumption to depositors depending on their announcements. ${ }^{2}$ For example, Green and Lin (2003) add aggregate uncertainty about liquidity needs to the Diamond-Dybvig framework and assume that depositors know the order in which they have an opportunity to withdraw. The bank updates its belief about the type distribution after each decision and

\footnotetext{
${ }^{2}$ Usually a direct revelation mechanism is studied: when contacting the bank, depositors tell the bank their type. When a depositor announces to be impatient, the bank assigns her an optimal consumption based on the available information.
} 
optimizes the contract accordingly. As a result, complex contracts arise that are contingent on the exact sequence of announcements and payments to depositors may be fairly variable. Nevertheless, the Pareto efficient allocation is shown to be the unique equilibrium outcome. ${ }^{3}$

In the game theoretic approach, first the Pareto efficient allocation is found which a social planner would choose if she knew the type vector. Then, the outcome of a game is studied assuming that types are imperfect information. In the Diamond-Dybvig setup with aggregate certainty about liquidity types the first best yields an optimal simple demand deposit contract that determines how much the bank should pay to those who withdraw early and together with the number of early withdrawals consumption in the second period is determined. If the game is specified as a simultaneous-move game, then a bank run and a no bank run equilibrium arise.

Diamond and Dybvig (1983) show that even if the optimal simple demand deposit contract is maintained, the Pareto efficient allocation becomes the unique equilibrium outcome if the simultaneous-move game is complemented by a suspension of convertibility clause. It stipulates that, after a certain number of withdrawals, payment to subsequent depositors is suspended, guaranteeing the bank enough money to pay later. As a consequence, the mere expectation of suspension is enough to rule out bank runs. Ennis and Keister (2009a, 2010b) show that suspension of convertibility is successful only if the bank can commit to use it as announced. The bank may fail to do so, since once a bank run is underway, suspension may not be ex post optimal: many depositors receive no money though they need liquidity. The bank may then attend needy depositors which are exempted from suspension as it happened during the deposit freezes in Argentina in 2001 or in the US in March 1933 (see Ennis and Keister, 2009a). During these episodes, payments were rescheduled but made to those who demonstrated urgent need for money, so suspension was not effective. If this lack of commitment is

\footnotetext{
${ }^{3}$ Ennis and Keister (2009b) show that this result fails to hold for correlated types.
} 
anticipated by the depositors, then suspension becomes ineffective ex ante and bank runs may occur. Therefore, other arrangements have to be found that may prevent bank runs even in a setup without aggregate uncertainty about liquidity needs. ${ }^{4}$

Ennis and Keister (2010a) point out that the contract that implements the optimal allocation in the Green-Lin model, mentioned above, is highly contingent on the available information, and hence results in volatile payments to depositors of the same liquidity type. However, in reality, we observe stable payments to depositors and the face value of deposits is respected most of times. These features are more akin to the simple demand deposit contract á la Diamond and Dybvig (1983). We maintain this optimal simple demand deposit contract and change the game by allowing the exact sequence of previous actions to be observed, though not the liquidity type vector. ${ }^{5}$

While it is intuitive that withdrawals can be observed, the empirical studies cited above suggest that, at least to some extent, even waiting is observable. Kelly and O Grada (2000) show that the most important factor determining whether an individual panicked or not in New York during a bank run episode in the 19th century was his country of origin in Ireland. This common origin presumably had an effect since immigrants from the same country clustered in the same neighborhood and observed each other. Iyer and Puri (2012) stress the importance of observing decisions of both sorts in one's social network when studying a bank run that occurred in India in 2001. In Starr and Yilmaz (2007), small and medium-sized depositors of an Islamic bank in Turkey seemed to observe only withdrawals of their peers during a bank run incident in 2001, but the behavior of large depositors appears to

\footnotetext{
${ }^{4}$ Diamond and Dybvig (1983) study how deposit insurance may prevent bank runs, though Wallace (1988) shows that the proposed approach is flawed since it is based on taxation that is infeasible if impatient depositors need their funds urgently.

${ }^{5}$ In Chari and Jagannathan (1987) and in Gu (2011), depositors try to infer the bank's uncertain asset quality based on noisy private signals and other depositors' observed decisions. The focus is on the signal extraction problem rather than the coordination problem. In section 3.4, we tackle the issue of information extraction.
} 
be affected by observing both actions.

Our paper shows that no bank run is the unique equilibrium outcome if the history of previous actions is observed. The paper closest to ours regarding the emphasis put on observability is Andolfatto et al. (2007) who are the first to assume the observability of the history of announcements. In the spirit of Green and Lin (2003), they use a mechanism design approach in an environment characterized by aggregate uncertainty about liquidity needs and show that any allocation that is implementable is also strongly implementable. The role of observability is intricate. On the one hand, knowing the complete history allows a depositor to condition her action on it. This strengthens the incentive compatibility constraints, implying that fewer allocations are implementable. On the other hand, a depositor prefers to announce her type truthfully if she believes that those who follow her will do so as well. In that sense, observing previous decisions does not affect the optimal decision. Contrary to Andolfatto et al. (2007), we assume that the bank pays the same amount of money to withdrawing depositors as long as it has funds left. In our model, the bank may run out of funds, leaving depositors who wish to withdraw unpaid. This cannot happen in Green and Lin (2003) or Andolfatto et al. (2007). Depositors in our paper condition their choice on the history of previous decisions and we consider all possible histories after which a depositor is asked to decide. In a Perfect Bayesian Equilibrium, early depositors correctly anticipate to be on the equilibrium path, take the optimal decision and lead the game down the path to the unique equilibrium outcome with no bank run.

The paper is organized as follows. Section 2 introduces notation and defines the model. In section 3, we provide examples and the general results, while section 4 concludes the paper. All proofs are relegated to the appendix. 


\section{The model}

There are three time periods denoted by $t=0,1,2$, and a finite set of depositors denoted by $I=\{1, \ldots, N\}$, where $N>2$. The consumption of depositor $i \in I$ in period $t=1,2$ is denoted by $c_{t, i} \in \mathbb{R}_{+}^{0}$, and her liquidity type by $\theta_{i}$. This is a binomial random variable with support given by the set of liquidity types $\Theta=\{1,2\}$. If $\theta_{i}=1$, depositor $i$ is called impatient, that is, she only cares about consumption at $t=1$. If $\theta_{i}=2$, depositor $i$ is called patient. Given $\theta_{i} \in\{1,2\}$, each depositor $i$ 's utility function is given by

$$
u_{i}\left(c_{1, i}, c_{2, i}, \theta_{i}\right)=u_{i}\left(c_{1, i}+\left(\theta_{i}-1\right) c_{2, i}\right)
$$

It is assumed to be strictly increasing, strictly concave, twice continuously differentiable and to satisfy the Inada conditions. The relative risk-aversion coefficient, $-c_{i} u_{i}^{\prime \prime}\left(c_{i}\right) / u_{i}^{\prime}\left(c_{i}\right)$, is assumed to be strictly larger than 1 , for all $c_{i} \in \mathbb{R}_{+}$, and all $i \in I$.

At $t=0$, each depositor has one unit of a homogeneous good which she deposits in the bank. The bank has access to a constant-return-to-scale productive technology which pays a gross return of one unit for each endowment liquidated at $t=1$, and a fixed return of $R>1$ for each endowment liquidated at $t=2 \cdot{ }^{6}$ It offers a simple demand deposit contract which pays $c_{1}^{*}$ to any depositor $i$ who withdraws at $t=1$, as long as the bank has funds left, and the same pro rata share of funds available to all depositors who wait until $t=2$.

The number of patient depositors is assumed to be constant and given by $p \in\{1, \ldots, N\}$ and the remaining depositors are impatient. The number of patient and impatient depositors is common knowledge. However, each depositor's type is only realized at $t=1$.

Let $\Theta^{N}=\{1,2\}^{N}$, and $\theta^{N}=\left(\theta_{1}, \ldots, \theta_{N}\right)$ denote the sequence of depositors, also called (liquidity) type vector. The set of sequences of length $N$

\footnotetext{
${ }^{6}$ We follow the literature (Diamond and Dybvig, 1983; Green and Lin, 2003; Ennis and Keister, 2009a) when assuming that there is no fundamental uncertainty about the return.
} 
with $p$ patient depositors is given by

$$
\Theta^{N, p}=\left\{\theta^{N} \in \Theta^{N}: \sum_{i=1}^{N}\left(\theta_{i}-1\right)=p\right\}
$$

There are $\left(\begin{array}{l}N \\ p\end{array}\right)$ possible type vectors. At $t=1$, one is selected randomly by a process which selects each of them with equal probability. Under imperfect information, the realized liquidity type vector is unobserved both by the depositors and the bank, while it is observable under perfect information.

Next, the Pareto efficient allocation is derived. A social planner could maximize the sum of depositors' utilities (which are assumed to be identical, except of the liquidity type) with respect to $c_{1, i}$ and $c_{2, i}$ subject to a resource constraint and to the commonly known number of patient and impatient depositors, $p$ and $N-p$, respectively. The first best allocation solves

$$
\begin{gathered}
\max _{c_{1, i}, c_{2, i}}(N-p) u_{i}\left(c_{1, i}\right)+p u_{i}\left(c_{2, i}\right) \\
\text { s. t. }(N-p) c_{1, i}+\frac{p}{R} c_{2, i}=N .
\end{gathered}
$$

The solution to this problem is

$$
u^{\prime}\left(c_{1}^{*}\right)=R u^{\prime}\left(c_{2}^{*}\right)
$$

which, as in Diamond and Dybvig (1983), implies that $R>c_{2}^{*}>c_{1}^{*}>1$. In the first best allocation, all impatient depositors consume $c_{1}^{*}$ at $t=1$, and all patient ones $c_{2}^{*}$ at $t=2$. Hence, patient depositors receive a higher consumption than impatient ones.

\subsection{Strategies and equilibrium concept}

A sequential service constraint is assumed to hold, that is, at $t=1$, the depositors contact the bank sequentially in the order given by $\theta^{N}$, and the payment to any withdrawing depositor only depends on the history, but not on the decisions of subsequent depositors, as will be specified below. 
Depositor $i$ 's strategy $\mathbf{s}_{i} \in\{1,2\}$ is to announce a type from $\Theta$. When type 1 or 2 is announced, she wishes to consume at $t=1$ (i.e., withdraw) or at $t=2$ (i.e., wait), respectively. Anonymity is assumed, that is, the depositors' indexes do not reveal any information. Each depositor $i$ is assumed to observe the entire history of previous type announcements $s^{i-1}=\left(s_{1}, \ldots, s_{i-1}\right)$, where $s^{i-1} \in \Theta^{i-1}$. Depositor $i$ 's strategy is conditional on the history and her type. It is defined as $\mathbf{s}_{i}: \Theta^{i-1} \times \Theta \rightarrow \Theta$. Let $\mathbf{S}=\{1,2\}^{N}$ be the game's strategy space, and let $\mathbf{s} \in \mathbf{S}$ be a strategy profile, that is, $\mathbf{s}=\left(\mathbf{s}_{1}, \ldots, \mathbf{s}_{N}\right)$. In order to emphasize depositor $i$ 's strategy, $\mathbf{s}$ is sometimes written as $\left(\mathbf{s}_{i}, \mathbf{s}_{-i}\right)$.

Given strategy profile $\mathbf{s} \in \mathbf{S}$, depositor $i$ 's consumption is specified by $c_{i}=\left(c_{1, i} ; c_{2, i}\right)$, where $c_{1, i}: \boldsymbol{\Theta}^{i} \rightarrow \mathbb{R}_{+}^{0}$, and $c_{2, i}: \boldsymbol{\Theta}^{N} \rightarrow \mathbb{R}_{+}^{0}$. The consumption of all depositors is feasible if $\sum_{i=1}^{N}\left(c_{1, i}+\frac{c_{2, i}}{R}\right) \leq N$. Depositor $i$ 's period-1 consumption is then defined as

$$
c_{1, i}= \begin{cases}c_{1}^{*}, & \text { if } s_{i}=1 \text { and } N-\sum_{j=1}^{i-1}\left(2-s_{j}\right) c_{1}^{*} \geq c_{1}^{*}, \\ y, & \text { if } s_{i}=1 \text { and } 0<N-\sum_{j=1}^{i-1}\left(2-s_{j}\right) c_{1}^{*}<c_{1}^{*}, \\ 0, & \text { otherwise }\end{cases}
$$

where $y=N-\sum_{j=1}^{i-1}\left(2-s_{j}\right) c_{1}^{*}:$ until the bank runs out of funds, any depositor who announces to be impatient receives a positive consumption $c_{1}^{*}$ or $y$.

Let $\eta \in\{0, \ldots, p\}$ be the number of depositors who wait at $t=1$, that is, each of them announces to be of type $2 .{ }^{7}$ Given $\eta=\frac{1}{2} \sum_{i=1}^{N} s_{i} \geq 0$, all players who wait at $t=1$, obtain the same consumption at $t=2$, namely,

$$
c_{2}(\eta)=\max \left\{0, \frac{R\left(N-(N-\eta) c_{1}^{*}\right)}{\eta}\right\}
$$

If $\eta=p$, only impatient depositors withdraw at $t=1$, and $c_{2}(\eta)=c_{2}^{*}>c_{1}^{*}$. Then, patient depositors enjoy a higher consumption than impatient ones.

\footnotetext{
${ }^{7}$ Note that $\eta$ is restricted to be equal to $p$ or smaller since an impatient depositor has a dominant strategy to withdraw, and thus, not more than $p$ depositors will wait.
} 
The consumption in both periods depends on the strategy profile and determines each depositor's utility. For any $i \in I$, and any $\mathbf{s} \in \mathbf{S}$, this is denoted by $u_{i}(\mathbf{s})$. Thus, $u_{i}$ is a mapping from $\mathbf{S}$ to $\mathbb{R}_{+}^{0}$. Let the tuple $(I, \mathbf{S}, u)$ be the bank run game, where $u=\left(u_{1}, \ldots, u_{N}\right)$.

Any depositor $i$ observes history $s^{i-1}$, knows her type $\theta_{i}$ and the commonly known parameters $p$ and $N$. However, under imperfect information, she does not observe the realized type vector and both patient and impatient depositors may choose to withdraw. Therefore, given the available information, she forms beliefs about the type vector that was selected by nature. Let $\mu_{i} \equiv \mu_{i}\left(\theta^{N} \mid s^{i-1}, \theta_{i}\right)$ denote depositor $i$ 's belief about the type vector. This belief is conditional on the history and $i$ 's type and is updated according to Bayes' rule whenever possible. The belief together with a strategy profile defines a Perfect Bayesian Equilibrium.

Definition 1. Given a bank run game. Then, strategy profile $\mathbf{s} \in \mathbf{S}$ and belief system $\mu=\left(\mu_{1}, \ldots \mu_{N}\right)$ are a Perfect Bayesian Equilibrium (PBE) if, and only if, for all $i \in I$, given $\theta_{i}, s^{i-1}$ and any $\tilde{\mathbf{s}}_{i} \in\{1,2\}$,

$$
\sum_{\theta^{N} \in \Theta^{N}} \mu_{i}\left(\theta^{N} \mid s^{i-1}, \theta_{i}\right) u_{i}(\mathbf{s}) \geq \sum_{\theta^{N} \in \Theta^{N}} \mu_{i}\left(\theta^{N} \mid s^{i-1}, \theta_{i}\right) u_{i}\left(\tilde{\mathbf{s}}_{i}, \mathbf{s}_{-i}\right),
$$

where $\mu_{i}\left(\theta^{N} \mid s^{i-1}, \theta_{i}\right)$ is consistent with Bayes' rule whenever possible.

A strategy profile and belief system are a PBE if, and only if, the strategy is sequentially rational given the belief for all players and the belief is consistent with the strategy (see Fudenberg and Tirole, 1991, and Myerson, 1997). Moreover, there are consistency requirements on the beliefs that arise from the fact that $p$ and $N$ are commonly known and also since an impatient depositor's dominant strategy is to withdraw. These are discussed in more depth in the section on imperfect information below. 


\section{Results}

The simple demand deposit contract defined above yields the Pareto efficient allocation (see Diamond and Dybvig, 1983). Our goal is to show that this allocation is the unique PBE outcome of the bank run game.

Given $p, N$ and $c_{1}^{*}$, it is possible to determine how many patient depositors have to wait in order for waiting to be an optimal strategy for each of them. In Lemma 1, one part of this threshold is derived, ${ }^{8}$ namely, the one (denoted as $\bar{\eta}$ ) such that $c_{2, i}>c_{1}^{*}$, for every patient depositor $i$ who waits at $t=1$. If some patient depositor declares to be impatient, then the bank spends funds on her which it would otherwise have kept until $t=2$. Recall that $\eta$ is the number of patient depositors that wait.

Lemma 1. Given $p, N$ and $c_{1}^{*}$, there is a unique $\bar{\eta}$ such that $1 \leq \bar{\eta} \leq p$, and for every patient depositor $i$ for whom $\mathbf{s}_{i}=2, c_{2, i}(\eta) \leq c_{1}^{*}$, for all $\eta \leq \bar{\eta}$, and $c_{2, i}(\eta)>c_{1}^{*}$, for all $\eta>\bar{\eta}$.

The proof of Lemma 1 can be found in Appendix A.

\subsection{The type vector is perfect information}

The benchmark case with perfect information is studied next. The depositors commonly know the number of patient depositors $p$, and each depositor's type, or in other words, the type vector selected randomly by nature.

Any impatient depositor $i$ has a dominant strategy to withdraw, and thus, $s_{i}\left(s^{i-1}, \theta_{i}=1\right)=1$ given any $s^{i-1}$. By eliminating uncertainty about the type vector we can apply standard backward induction arguments to find the equilibrium in Proposition $1 .^{9}$

\footnotetext{
${ }^{8}$ The other part is a technical detail which is derived below in Proposition 1's proof.

${ }^{9}$ Given that types are observable, the bank could directly impose the first best allocation by denying to pay to patient depositors.
} 
Proposition 1. Given a bank run game. Suppose that the type vector is perfect information. Then, the Pareto efficient allocation is the unique PBE outcome and depositors tell the truth.

Proposition 1's proof can be found in Appendix B. Since the type vector is of perfect information, the concepts of subgame perfect equilibrium and PBE coincide. Intuitively, the last patient depositor's optimal decision is to wait if enough preceding patient depositors waited so that her consumption in period 2 is higher than that received upon immediate withdrawal. Anticipating this decision, the next to last patient depositor's optimal decision is of the same nature, and by moving backward all patient depositors wait.

\subsection{The type vector is imperfect information}

When the type vector is not observable, depositors cannot apply the previous reasoning. Nevertheless and as before, they commonly know $p$ and $N$, and that nature selects each type vector with equal probability. Moreover, each depositor knows her own type and observes the history. This is referred to as available information. Given the available information, a depositor forms beliefs about the type vector selected by nature and, by sequential rationality, anticipates how subsequent depositors behave. In this environment of imperfect information, sequential rationality plays a similar role as backward induction in games of perfect information (see Myerson, 1997). Before proving the general result, the difficulties that arise are illustrated in an example.

\subsubsection{Example}

Suppose that there are four depositors: one is impatient and the other three are patient. Before the game begins, nature selects each of the four possible type vectors with equal probability. Once the type vector is selected, each depositor observes her type but not any other's. Then, they take decisions in a sequential order. Moreover, we make the following assumption. 
Assumption 1. All three patient depositors have to keep the money in the bank in order to make waiting worthwhile for all of them.

We depict the corresponding extensive form of the game in Figure 1, where $p$ stands for patient, $i$ for impatient, keep for wait, and wi for withdraw, and where the outcome of each branch of the game is depicted, that is, bank run and no bank run, respectively. A bank run occurs if at least one patient depositor withdraws. Several information sets are not singletons: for instance, a patient depositor 2 who observes a withdrawal could be in a type vector that starts with a patient depositor who decided to withdraw or in the type vector that begins with the impatient depositor. Finally, in order to simplify the figure, we suppose that each impatient depositor withdraws since this is a dominant strategy for her, as is shown below.

Suppose that each depositor deposits 1 unit in the bank at $t=0$ and let $u_{i}=c_{1}+\left(\theta_{i}-1\right) c_{2}$ for all $i, c_{1}^{*}=1.5$ and $R=1.9$. Then, $c_{2}$ is obtained by multiplying the funds left at $t=2$ by 1.9 and dividing them by the number of depositors that waited at $t=1$. It is easy to calculate that after two withdrawals 3 of the 4 units deposited in the bank are gone and any remaining depositor is strictly better off to withdraw the remaining funds of 1 at $t=1$ rather than to wait: if two depositors wait, then at $t=2$, the total funds left are 1.9 which yields $\frac{1.9}{2}$ for each of them and this is less than 1 . So any subsequent depositor is better off to withdraw the remaining funds, and therefore, this example fulfils Assumption 1.

Now we identify all possible strategy profiles that can arise given the set of depositors, their types and strategies. This provides a complete description of all possible equilibrium candidate strategy profiles:

- Pooling equilibrium candidate: all depositors choose the same action.

- Separating equilibrium candidate: all depositors of one type choose the same action, and that of the other type the other action. 


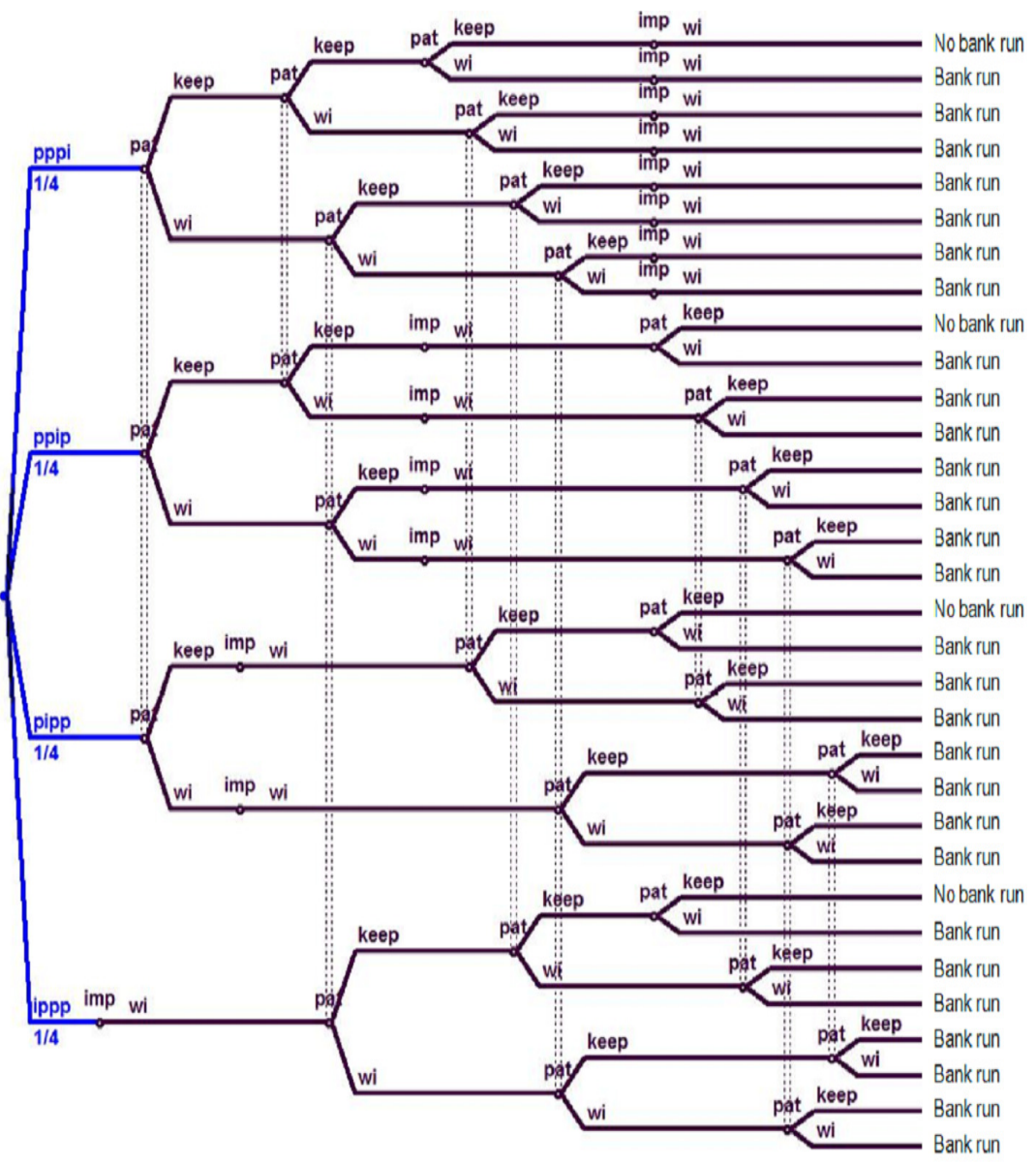

Figure 1: Extensive form game of example 
- Any other equilibrium candidate: the impatient depositor waits or withdraws, at least one patient depositor waits and at least one patient depositor withdraws.

Obviously, any impatient depositor $i$ is never strictly better off to withdraw since $\theta_{i}=1$ for her. So any candidate strategy profile which contains such a case is never a PBE. In all remaining cases, the impatient depositor withdraws, while the patient depositors withdraw in a pooling equilibrium, wait in a separating equilibrium, and in any other case at least one of them waits and at least one of them withdraws.

Deriving the PBE Now we will go through the three candidate strategy profiles that are left. Consider first the separating PBE candidate: independently of the realized type vector, on the equilibrium path, each patient depositor waits, while the single impatient depositor withdraws.

Impatient depositor: Since an impatient depositor has a dominant strategy to withdraw, her strategy is optimal after any history and given any belief. ${ }^{10}$ She has no profitable deviation from withdrawing and, given that she is impatient, her updated prior belief assigns probability 1 to the true type vector selected by nature since the other three depositors are patient.

Patient depositors: Consider now a patient depositor's complete strategy and belief system for the four possible positions she can have.

Depositor 4: On the equilibrium path, there are two patient depositors before her who waited and an impatient one who withdrew. Hence, she identifies the type vector and, by Bayesian belief updating, $\mu_{4}$ assigns probability 1 to the true type vector selected by nature.

To wait yields her $u_{4}=\frac{1}{3}(4-1.5) 1.9=1.58$, while she gets $u_{4}=1.5$ if she withdraws, and she is strictly better off to wait. Her strategy is sequentially rational given her belief and her belief is consistent with the strategy.

\footnotetext{
${ }^{10}$ Though on an off-equilibrium path on which the bank ran out of funds she is indifferent to wait or not since her utility is 0 anyway, and thus, her strategy is not strictly dominant.
} 
Suppose next that she observes an off-equilibrium path history. After history $(2,1,1)$ or $(1,2,1)$, her belief updating is unconstrained since both histories have an ex ante 0-probability. After history $(1,1,2)$ or $(1,1,1)$, depositor 4 updates $\mu_{4}$ according to Bayes' rule, though depositor 3 updated $\mu_{3}$ after an unexpected history in an unconstrained way.

If there were three withdrawals, then all 4 units deposited in the bank are gone and depositor 4 receives 0 in any case. Hence, she can neither deviate profitably by waiting nor by withdrawing. If two depositors withdrew and one waited, then there is 1 unit left in the bank. In case depositor 4 waits she gets, as derived above, $\frac{1.9}{2}<1$, and she is strictly better off to withdraw the remaining funds of 1 at $t=1$. Her decision is sequentially rational given the observed history and any consistent belief, and any belief is consistent with the strategy.

Suppose next that depositor 4 observes history $(2,2,2)$, that is, all three preceding depositors waited. On this off-equilibrium path, depositor 4's expected utility is higher if she waits since this yields her a payoff of 1.9 instead of 1.5 if she withdraws. Her decision is independent of her belief, that is, for any consistent belief she may have, her strategy is sequentially rational.

Depositor 3: There are four possible histories a patient depositor 3 can observe. After histories $(2,2),(2,1)$ and $(1,2)$, she believes to be on the equilibrium path and Bayesian belief updating assigns probability 1 to type vectors $(2,2,2,1),(2,1,2,2)$ and $(1,2,2,2)$, respectively. In the first case, depositor 3 is the third depositor that waits. In the last two cases, she is the second that waits, but believes with probability 1 that depositor 4 is patient and by sequential rationality anticipates that depositor 4 will wait.

If she and two more depositors wait, then her utility is $u_{3}=1.58$, while it is 1.5 if she withdraws. Since her belief assigns probability 1 to a type vector in which the three patient depositors wait, she is strictly better off to wait. Her strategy is sequentially rational given her belief, and her belief is consistent given the strategy. 
Finally, suppose that she observes history $(1,1)$, that is, the only possible off-equilibrium path history a patient depositor 3 can identify as such. Since this history has an ex ante 0 -probability, belief updating is unconstrained. In any case, if she withdraws, then she receives a utility of 1 , while she receives a utility of 0 if she waits, since depositor 4 , after observing two withdrawals, as just derived, would then withdraw the remaining funds of 1. Her strategy is optimal given the observed history and there are several consistent beliefs. Depositor 2: She either observes that depositor 1 waits or withdraws. In both cases, her observation is consistent with the equilibrium path. After observing a waiting, her belief $\mu_{2}$ assigns probability $\frac{1}{2}$ respectively to type vectors $(2,2,1,2)$ and $(2,2,2,1)$, and after observing a withdrawal, $\mu_{2}$ assigns probability 1 to type vector $(1,2,2,2)$. Both beliefs are updated by Bayes' rule and are consistent with her observing the strategy profile in which all patient depositors wait.

If she observes a waiting and waits herself, by sequential rationality, she anticipates that the last patient depositor behind her waits, and if she observes a withdrawal, then she believes that the two remaining depositors after her in the queue are patient and will wait, as derived above. Her expected utility by waiting is $u_{2}=1.58$, and it is 1.5 if she withdraws. To wait yields her a higher expected utility. Depositor 2's belief $\mu_{2}$ is consistent with the strategy profile which is sequentially rational given her belief.

Depositor 1: She knows that she is patient and her belief $\mu_{1}$ assigns an equal probability of $\frac{1}{3}$ to type vectors $(2,2,2,1),(2,2,1,2)$ and $(2,1,2,2)$, respectively. By sequential rationality, she anticipates that, on the equilibrium path, the other two patient depositors wait, since their reasoning is as derived above. Her expected utility by waiting is $u_{1}=1.58$, while it is 1.5 if she withdraws. To wait yields her a higher utility. Belief $\mu_{1}$ is consistent with the strategy profile which is sequentially rational given her belief.

Given this strategy, any depositor's decision on the equilibrium path is fully revealing for the subsequent depositors and no bank run is a PBE. 
On the equilibrium path, any other belief system is not consistent with the strategy profile and the available information since it assigns a positive probability to a depositor who withdraws to be patient or to a depositor who waits to be impatient or both. However, on some off-equilibrium path, while the depositors' strategies are optimal given the observed history, their belief updating is unconstrained and there are several possible consistent beliefs. Hence, there are multiple PBE strategy profiles which differ by depositors' beliefs and strategies off the equilibrium path. Yet, given any consistent belief system, the strategy profile is a PBE and yields no bank run as outcome.

Uniqueness of PBE outcome We show next that the pooling equilibrium candidate in which all three patient depositors withdraw is no PBE since some patient depositor has a profitable deviation. Thereafter, we do the same for any remaining strategy profiles in which at least one patient depositor waits and at least one withdraws. In this way, we consider all possible strategy profiles, and after showing that a bank run is never a PBE outcome, it follows that no bank run is the unique PBE outcome.

Pooling PBE candidate: all depositors withdraw Since the impatient depositor's dominant strategy is to withdraw, we focus on the decision of patient depositors. A patient depositor 4 observes three withdrawals on the proposed equilibrium path. Since this implies that the bank is bankrupt she is indifferent to wait or withdraw and has no profitable deviation from withdrawing. Her utility is 0 in any case and she withdraws.

In order to analyze her off-equilibrium behavior, we focus on a specific history for which we will show that some depositor has a profitable deviation.

Suppose that on an off-equilibrium path, a patient depositor 4 observes that two depositors waited before her. Then, identically as above, waiting yields her $u_{4}=1.58$ and withdrawing $u_{4}=1.5$, and she is strictly better off to wait. This is sequentially rational for her given the observed history. While the depositor who observes the first waiting updates her belief in an 
unconstrained way since she finds herself on an off-equilibrium path, depositor 4 updates her belief based on this in a Bayesian way. Thus, $\mu_{4}$ could assign probability 1 to the type vector in which the depositor who withdrew is impatient. This belief is consistent with this off-equilibrium path strategy which in turn is sequentially rational given her belief.

On the equilibrium path, a patient depositor 3 observes two withdrawals and is strictly better off to withdraw the remaining funds of 1 rather than to wait. Suppose that on an off-equilibrium path she observes that two depositors waited before her. Then, by waiting she receives a strictly higher utility of 1.58 than by withdrawing which only yields 1.5 , and it is sequentially rational for her to wait given the observed history. Similarly as before, updated belief $\mu_{3}$ could assign probability 1 to the type vector in which the last depositor is impatient. This belief is consistent with the available information and the strategy which is sequentially rational given her belief.

Suppose now that a patient depositor 3 observes that depositor 1 waited and depositor 2 withdrew. Then, depositor 3 is strictly better off to wait rather than to withdraw since this yields her a higher expected utility. She anticipates, by sequential rationality, that depositor 4 will wait and that a patient depositor 2 would have waited upon observing that depositor 1 waited, as will be derived next. Her belief $\mu_{3}$ could assign probability 1 to the type vector in which depositor 2 is impatient. Her belief is consistent with the strategy which is sequentially rational given her belief.

Consider now a patient depositor 2. On the equilibrium path, she observes one withdrawal and cannot update her belief from the prior. Thus, she is strictly better off to withdraw rather than to wait. Suppose that on an offequilibrium path she observes that depositor 1 waits. Since this history has an ex ante 0-probability her belief updating is unconstrained. However, it is consistent for a patient depositor 2 to believe that it is equally likely for the impatient depositor to be in the third or fourth position, respectively, and for the third patient depositor to be in the other. By sequential rationality 
and as just derived, she anticipates that, if she waits, then the last patient depositor in the queue will wait as well. This yields her a higher expected utility and she waits. Her belief is consistent with the strategy which in turn is sequentially rational given her belief.

On the equilibrium path, a patient depositor 1 should withdraw. However, she can increase her expected utility by deviating, that is, by waiting. By sequential rationality, she anticipates that then the second patient depositor waits, as just derived, independently of whether she is in position 2 or 3 . Then, the last patient depositor in the queue, as just derived, is strictly better off to wait as well upon observing two waitings. Hence, there is no bank run. Depositor 1 cannot update her prior: yet her belief is consistent given the strategy profile which is sequentially rational given her belief.

Given this strategy profile and any type vector in which depositor 1 is patient, there is no bank run since depositor 1 has a profitable deviation to lead the game onto an off-equilibrium path on which all patient depositors wait. Therefore, for all depositors to withdraw is no PBE since there is a type vector such that some depositor has a profitable deviation.

Any other PBE candidate Similarly, any other strategy profile in which one or two patient depositors are asked to withdraw is no PBE. Consider first that two patient depositors are asked to wait and one to withdraw. Suppose that the type vector is such that depositors 1 and 2 are patient and both wait. Then, the last patient depositor in the queue is asked to withdraw. However, analogously as before, she deviates profitably by waiting.

Suppose next that two patient depositors are asked to withdraw and one to wait. If depositor 1 is patient and waits then, analogously as above, it is sequentially rational for the remaining two patient depositors to wait as well. The first one has a profitable deviation to wait rather than to withdraw as prescribed, and the other is then strictly better off to wait once she observed two waitings since this yields her a higher utility than to withdraw. 
Therefore, any PBE candidate strategy profile that yields a bank run as outcome is no PBE since we have shown that for each of them there is a type vector such that some patient depositor has a profitable deviation. Hence, in this example, no bank run is the unique PBE outcome.

\subsection{The general case}

The arguments in the previous subsection are generalized in order to find the set of PBE for any bank run game and the unique PBE outcome is no bank run which is the Pareto efficient allocation.

Proposition 2. Given a bank run game. Suppose that the type vector is imperfect information. Then, the Pareto efficient allocation is the unique PBE outcome.

The proof of Proposition 2 can be found in Appendix C. Intuitively, in any $\mathrm{PBE}$, given the available information, it is consistent for a patient depositor to believe to be on the equilibrium path as long as there are $N-p$ or less withdrawals, that is, unless she observes a history which is incompatible with being on the equilibrium path. Given this belief, it obviously yields her a higher expected utility to wait. She waits and anticipates, by sequential rationality, that all other patient depositors behind her will wait as well. For each of them, an analogous reasoning applies and it is optimal to wait. This in turn generates a history which induces all other patient depositors to wait, while all impatient ones withdraw. No bank run is the unique PBE outcome. However, as in the example above, there are several PBE strategy profiles and belief systems which all are identical on the equilibrium path, though they differ on off-equilibrium paths.

Analogously to the example, given any other strategy profile, there is a type vector for which some patient depositor has a profitable deviation and by leading the game down an off-equilibrium path, all patient depositors are better off to wait. By doing this, each of them receives a higher payoff. 


\section{Robustness considerations and discussion}

In this section first we deal with the robustness of our assumptions and then we discuss some interesting directions for future research.

\subsection{Robustness of assumptions}

An interpretation of our main result is the following. Depositors deciding sequentially and observing all previous decisions is a sufficient condition to prevent bank runs. It is natural to ask what are the necessary conditions, that is, does the result hold if we relax either i) assumptions about the information, or ii) other assumptions related to uncertainty.

\subsubsection{Exogenous sequence of decisions}

We assume that the sequence of moves is exogenously determined after a random draw which selects each sequence with equal probability. This assumption follows the literature (Green and Lin, 2003; Andolfatto et al., 2007; Ennis and Keister, 2009b). ${ }^{11}$ In this spirit, our paper is no attempt to formally making this sequence endogenous.

However, suppose that before the bank run game is played, the depositors play a game to determine endogenously the position they occupy in the queue. As shown in Propositions 1 and 2, no bank run is the unique equilibrium outcome given any sequence of depositors. To determine the sequence endogenously would not change this result: each depositor is indifferent of which position to occupy since the unique outcome is no bank run. The game is still solved by backward induction or sequential rationality, respectively,

\footnotetext{
${ }^{11}$ Ennis and Keister (2010a), in a literature survey, note that "[i]n the Diamond-Dybvig tradition, the order in which agents get an opportunity to withdraw is assumed to be exogenously given (generally determined by a random draw). In other words, agents in the model are not allowed to take explicit actions to change their order of arrival. This assumption is, of course, extreme and, unfortunately, not much is known so far about the case where it is not made."
} 
and therefore, the bank run game played after determining the sequence is resolved first and yields no bank run as unique outcome. Hence, depositors are indifferent regarding the position. In any case, assuming that indifferent depositors determine the order of moves endogenously resembles very much the assumption of a random draw of the sequence before the game begins. ${ }^{12}$

Finally, it should be noted that sequentiality (but not the order) seems to be a necessary condition since the original Diamond-Dybvig (1983) model is a simultaneous move game and has both a bank run and a no bank run equilibrium.

\subsubsection{Extent of observability}

The novel assumption of our model is that all previous choices are observed as they are made. ${ }^{13}$ This implies that each depositor knows her position in the queue. What would happen if this assumption does not hold? It may be violated in several ways.

First, suppose that only withdrawals are observed (and the position is not known, but depositors draw conclusions about it from the previously observed number of withdrawals). Consider the four-depositor example of section 3.2.1 and the following run candidate strategy for patient depositors: withdraw after 0,1 and 2 withdrawals. ${ }^{14}$ It is easy to see that there is no profitable unilateral deviation from the strategy. Even if a patient depositor waits instead of withdrawing, then this is not observed, so if the other patient depositors follow the proposed strategy then the deviation does not pay off. Hence, bank run is an equilibrium outcome.

Second, it is possible that some depositors do not observe each other. As-

\footnotetext{
${ }^{12}$ This conclusion would not hold any longer if the bank had fundamental problems since then the informed depositors have an incentive to be at the beginning of the sequence.

${ }^{13}$ While Andolfatto et al. (2007) assume observability of the history as well, their approach is based on mechanism design, while ours is game theoretic.

${ }^{14}$ After 3 withdrawals the bank ran out of funds, so a depositor is indifferent to wait or withdraw. Note also that in this setup a strategy can only depend on the number of observed withdrawals.
} 
sume, for instance, that in our four-depositor example, depositor 2 does not observe depositor 1's decision and this is commonly known. All other depositors observe all previous decisions. We propose the following run candidate strategy for patient depositors: withdraw in position 1 and 2, withdraw in position 3 and 4, unless you observe at least two waitings and wait otherwise. Note that a patient depositor in position 2 has no profitable unilateral deviation given the withdrawal of depositor 1 and the strategies of the subsequent depositors and the same is true for a patient depositor 1. In Proposition 2, this strategy profile is no PBE since depositor 1 has a profitable deviation to

wait, depositor 2 observes this and is also strictly better off to wait bringing the game on a path that results in no bank run. The lack of observability between depositors 1 and 2 would make bank run an equilibrium outcome.

The previous reasoning suggests that if perfect observability is violated, then bank run re-emerges as an equilibrium outcome. Undoubtedly, more research is needed to establish necessary conditions to prevent bank runs, though the above arguments indicate that the available information about previous choices should be very exhaustive.

\subsection{Discussion}

We discuss briefly two ways that seem promising to extend the model and how they affect or modify our results.

\subsubsection{Information Extraction Problem}

In our analysis, one of the main assumptions is that the bank has no fundamental problem. Hence, a bank run could only be triggered by depositors' miscoordination. In reality, frequently, there is an additional information extraction problem, that is, the depositors are not sure whether the bank has fundamental problems or not, and they make inferences based on the observed decisions. In this case, our results need to be qualified. However, 
to study an information extraction problem under the assumption that the bank is not fundamentally healthy is left for future research.

\subsubsection{Uncertainty}

Uncertainty could be introduced in various ways. Suppose first that each depositor is crazy or irrational with a very small probability, that is, a patient depositor withdraws while an impatient one waits. As long as the corresponding probabilities are small, our result does not change. Suppose that each depositor is irrational with a minor probability of $\varepsilon>0$ and is rational with a complementary probability of $(1-\varepsilon)$. Irrationality is assumed to be independently and identically distributed among depositors. Then, our results of Propositions 1 and 2 carry over to the case with irrationality. We call this the bank run game with irrational depositors.

Corollary 1. Given a bank run game with irrational depositors. Then, there is $\bar{\varepsilon}>0$ close enough to 0 , such that for all $0<\varepsilon<\bar{\varepsilon}$, the unique PBE outcome is almost surely the one obtained in Propositions 1 and 2.

The proof of this corollary is straightforward and we sketch it briefly: Consider first the equilibrium candidate. As $\varepsilon$ converges to 0 , there is a value of $\bar{\varepsilon}>0$ such that each patient depositor almost surely is rational. Therefore, she almost surely waits. This is true for all patient depositors, and hence, almost surely there is no bank run. Similarly, this is true for any other candidate strategy profile that was shown to be no PBE above.

A second source of potential uncertainty concerns the share of impatient depositors. When there is some but little uncertainty about the fraction of impatient depositors, then the same results as before hold as long as not all patient depositors need to wait in order for waiting to be the optimal decision for all other patient depositors. When to the contrary uncertainty about the share of impatient depositors is sufficiently large, then our results need not hold any longer. However, the corresponding analysis is beyond the scope of 
this paper. ${ }^{15}$

Finally, consider that the bank's return is risky. In case the expected return $R$ of the bank is less than 1, then obviously, each depositor's payoff is strictly larger when she successfully withdraws her money at $t=1$. In order to analyze a meaningful problem, we therefore assume that the bank invests the money in a risky asset with expected return $R>1$ which is realized at the beginning of period 2 just before the bank returns money to all depositors that waited at $t=1$. If the expected return is high enough, so that it compensates even risk-averse depositors for the implied enhanced risks, then our results do not change.

It would be realistic and interesting to study how the three sources of uncertainty affect our results when their impact is sufficiently large. However, this is beyond the scope of our paper, and therefore, left for future research.

\section{Conclusion}

Descriptions of bank runs suggest that depositors' behavior depends crucially on other depositors' observed behavior. Existing theoretical models in the Diamond-Dybvig tradition, without aggregate uncertainty about liquidity needs, do not incorporate this idea, sequentiality is missing from them. We attempt to fill this gap and assume that depositors observe all previous decisions. We show that bank runs do not occur in equilibrium, even though the type of preceding depositors is not observed. This result contrasts starkly with the findings of previous models, and suggests that the insensitivity of the Diamond-Dybvig contract to aggregate liquidity needs need not lead to multiple equilibria, one of them being a bank run. If all previous decisions are observed, in our model, bank runs are no equilibrium outcome.

\footnotetext{
${ }^{15}$ If the bank maximizes depositors' expected utility given this kind of uncertainty, then the model changes substantially and resembles Green and Lin (2003). Note that - as already pointed out by Diamond and Dybvig (1983) - if the share of impatient depositors is not fixed, then the simple demand deposit contract cannot achieve optimal risk sharing.
} 
Two elements of the model contribute to the absence of bank runs. First, aggregate certainty enables coordination as it signals all patient depositors that it is in their interest to wait, that is, it is commonly known that a bank run never occurs if all of them wait. Moreover, this assumption is quite realistic most of times. Second, the sequentiality of moves together with the perfect observability of previous decisions ensure that this is the unique PBE outcome. This equilibrium concept imposes strong rationality requirements on the depositors in terms of beliefs and sequential rationality. Our result is robust to endogenizing the sequence of decisions, and to some uncertainty about the irrationality of depositors, the share of the different liquidity types and the riskiness of the technology that the bank invests in. However, it seems that the available information about the previous decisions should be highly detailed. Arguably, in reality depositors do not have this amount of information. Nevertheless, we think that our paper is useful for policy makers by stressing the importance of transparency. By making the decision to wait observable, for example, by publishing maturity data and convincing depositors to extend the maturity of their deposits, bank runs on fundamentally healthy banks due to coordination failure among depositors could be prevented.

\section{Acknowledgements}

We thank for helpful comments Iftekhar Hasan, the editor of the Journal of Financial Stability and two anonymous referees. This paper has benefited from suggestions provided by participants at the Annual Conference of the Hungarian Economic Association 2012. Kinateder kindly acknowledges financial support from the Spanish Ministry of Science and Innovation through grants ECO2012-34202 and ECO2010-18680. Kiss is grateful for financial support from the Spanish Ministry of Science and Innovation under the project ECO 2011-25349 and from the Hungarian Scientific Research 
Fund (OTKA) under the project PD 105934.

\section{References}

Andolfatto, D., Nosal, E., Wallace, N., 2007. The Role of Independence in the Green-Lin Diamond-Dybvig Model. Journal of Economic Theory 137 (1), 709-715.

Baba, N., McCauley, R., Ramaswamy, S., 2009. US dollar money market funds and non-US banks. BIS Quarterly Review, March.

Brunnermeier, M., 2001. Asset Pricing under Asymmetric InformationBubbles, Crashes, Technical Analysis, and Herding. Oxford University Press.

Calomiris, C. W., Mason, J. R., 2003. Fundamentals, panics, and bank distress during the depression. American Economic Review 93 (5), 16151647.

Chari, V. V., Jagannathan, R., 1988. Banking panics, information, and rational expectations equilibrium. The Journal of Finance 43 (3), 749-761.

De Graeve, F., Karas, A., 2014. Evaluating Theories of Bank Runs with Heterogeneity Restrictions. Journal of the European Economic Association $12(4), 969-996 .$.

Diamond, D.W., Dybvig, P.H., 1983. Bank Runs, Deposit Insurance and Liquidity. Journal of Political Economy 91 (3), 401-419.

Ennis, H., 2003. Economic fundamentals and bank runs. Economic Quarterly-Federal Reserve Bank of Richmond 89 (2), 55-71.

Ennis, H., Keister, T., 2009a. Bank Runs and Institutions: The Perils of Interventions. American Economic Review 99 (4), 1588-1607. 
Ennis, H., Keister, T., 2009b. Run equilibria in the Green-Lin model of financial intermediation. Journal of Economic Theory 144 (5), 1996-2020.

Ennis, H., Keister, T., 2010a. On the Fundamental Reasons for Bank Fragility. Federal Reserve Bank of Richmond Economic Quarterly 96 (1), 33-58.

Ennis, H., Keister, T., 2010b. Banking panics and policy responses. Journal of Monetary Economics 57 (4), 404-419.

Fudenberg, D., Tirole, J., 1991. Game Theory. MIT Press.

Garratt, R.J., Keister, T., 2009. Bank Runs as Coordination Failures: An Experimental Study. Journal of Economic Behavior \& Organization 71 (2), 300-317.

Gorton, G., 1988. Banking panics and business cycles. Oxford Economic Papers 40 (4), 751-781.

Gorton, G., Metrick, A., 2012. Securitized banking and the run on repo. Journal of Financial Economics 104 (3), 425-451.

Green, E.J., Lin, P., 2003. Implementing Efficient Allocations in a Model of Financial Intermediation. Journal of Economic Theory 109 (1), 1-23.

Gu, C., 2011. Herding and bank runs. Journal of Economic Theory 146 (1), 163-188.

Ivashina, V., Scharfstein, D., 2010. Bank lending during the financial crisis of 2008. Journal of Financial Economics 97 (3), 319-338.

Iyer, R., Puri, M., 2012. Understanding Bank Runs: The Importance of Depositor-Bank Relationships and Networks. American Economic Review 102 (4), 1414-1445. 
Kelly, M., O Grada, C., 2000. Market Contagion: Evidence from the Panics of 1854 and 1857. American Economic Review 90 (5), 1110-1124.

Kiss, H.J., Rodriguez-Lara, I., Rosa-García, A., 2012. On the Effects of Deposit Insurance and Observability on Bank Runs: An Experimental Study. Journal of Money, Credit and Banking 44 (8), 1651-1665.

Kiss, H.J., Rodriguez-Lara, I., Rosa-García, A., 2014. Do social networks prevent or promote bank runs? Journal of Economic Behavior and Organization 101, 87-99.

Myerson, R.B., 1997. Game Theory. Harvard University Press.

Schotter, A., Yorulmazer, T., 2009. On the dynamics and severity of bank runs: An experimental study. Journal of Financial Intermediation 18 (2), 217-241.

Starr, M.A., Yilmaz, R., 2007. Bank Runs in Emerging-Market Economies: Evidence from Turkey's Special Finance Houses. Southern Economic Journal $73(4), 1112-1132$.

Wallace, N., 1988. Another attempt to explain an illiquid banking system: The Diamond and Dybvig model with sequential service taken seriously. Federal Reserve Bank of Minneapolis Quarterly Review, 12 (4), 3-16.

\section{Appendix A}

Appendix A contains the proof of Lemma 1.

Proof. In order to derive the threshold value $\bar{\eta}$, a condition is found such that $c_{1}^{*}$ is strictly smaller than period- 2 consumption, that is,

$$
c_{1}^{*}<\frac{R\left(N-(N-\eta) c_{1}^{*}\right)}{\eta},
$$


where the right-hand-side is period- 2 consumption if $\eta$ depositors wait at $t=1$. Solving this inequality for $\eta$ yields

$$
\eta>\frac{R N\left(c_{1}^{*}-1\right)}{c_{1}^{*}(R-1)} .
$$

Denote by $[x]$ the integer part of any $x \in \mathbb{R}$. Since $\eta$ is a natural number, the previous condition becomes

$$
\eta>\left[\frac{R N\left(c_{1}^{*}-1\right)}{c_{1}^{*}(R-1)}\right] \equiv \bar{\eta} .
$$

The right-hand side of (3) defines the threshold value $\bar{\eta}$. This value is unique since the bank pays to every depositor who withdraws $c_{1}^{*}$, and therefore, loses funds monotonically. If there are too many withdrawals by patient depositors, then the bank only pays $c_{2, i}<c_{1}^{*}$ to every depositor $i$ who waits until $t=2$. If the number of patient depositors that wait $\eta$ is not larger than $\bar{\eta}$, as derived in (3), then period-2 consumption is strictly below $c_{1}^{*}$.

\section{Appendix B}

Appendix B contains the proof of Proposition 1.

Proof. We show that under perfect information, in the unique PBE which in this case is the unique subgame perfect equilibrium each depositor announces her type truthfully.

First, conditions are derived under which period-1 consumption is strictly larger than period-2 consumption and a patient depositor is better off to withdraw at $t=1$, that is, she declares to be impatient. Then, it is shown that this never occurs in equilibrium, the depositors' equilibrium strategies are derived and shown to be a PBE, and finally, uniqueness is established.

As shown in Lemma 1, if $\bar{\eta}$ or less patient depositors wait, then $c_{2, i}<c_{1}^{*}$ and a patient depositor is better off to withdraw as long as the bank pays 
her $c_{1}^{*}$. However, if there are further withdrawals, then at some point the bank has $0<y<c_{1}^{*}$ of funds left which she pays to the last depositor who withdraws. Once there are $y$ of funds left, if period-2 consumption is larger than or equal to $y$, then any patient depositor is better off to wait only if there is no more impatient depositor left in the queue who withdraws $y$. If, on the other hand, period- 2 consumption is smaller than $y$, then even a patient depositor is better off to withdraw $y$ at $t=1$, rather than to wait and get less at $t=2$. In this case, the depositor whose turn it is, once the bank has $y$ of funds left, withdraws $y$ independently of her type.

Now the depositors' complete strategy is derived: an impatient depositor always withdraws; a patient one withdraws if, and only if, her period-1 consumption is strictly larger than period-2 consumption. Otherwise, she waits. This is a subgame perfect equilibrium and a PBE of the bank run game if no depositor's deviation from this strategy profile is profitable. Any impatient depositor $i$ 's deviation to wait at $t=1$, yields her the same (if no funds are left in the bank) or a lower utility of $u_{i}=0$, since for her $\theta_{i}=1$, and thus, this deviation is not profitable. Consider now any patient depositor's unilateral deviation. If she withdraws instead of waiting, then her consumption is $c_{1}^{*}<c_{2}^{*}$, and this deviation is not profitable for her given that all other patient depositors wait under the proposed strategy profile. Consider next a history after which period-2 consumption is below period-1 consumption for a patient depositor since the conditions derived in the previous paragraph apply. Then, a patient depositor's strategy prescribes her to withdraw at $t=1$. She cannot deviate profitably by waiting which would yield her less.

Remember that the type vector is publicly observed. The subgame perfect equilibrium is found by backward induction. Any impatient depositor has a dominant strategy to withdraw at $t=1$. The last patient depositor waits if her consumption is $c_{2, i}>c_{1}^{*}$ or $c_{2, i}>y$. The next to last patient depositor waits if the identical condition holds anticipating (by backward induction) that then also the last patient depositor is strictly better off to wait. By 
induction, this is true for all patient depositors. Finally, by induction, also the first patient depositor waits, that is, all of them wait and each receives $c_{2}^{*}>c_{1}^{*}$. Applying backward induction, each depositor's decision is unique on the equilibrium path since none of them is ever indifferent. However, on any off-equilibrium path on which the bank ran out of funds, any depositor is indifferent to wait or withdraw since her utility is 0 independently of her strategy and type. Hence, there is a unique equilibrium outcome, while there are several subgame perfect equilibria and PBE which differ by the depositors' behavior on irrelevant off-equilibrium paths.

\section{Appendix $\mathrm{C}$}

Appendix C contains the proof of Proposition 2.

Proof. We prove Proposition 2 in various steps. Note that the complete description of all possible classes of equilibrium strategy profile candidates is identical to that in the example in section 3.2.1. We show first that any candidate in which some impatient depositor is prescribed to wait on the equilibrium path is no PBE. For the remaining classes, we then show whether the corresponding strategy profiles are PBE or not, and finally, it follows as a corollary that the unique equilibrium outcome is no bank run since the only class of strategy profiles that are PBE is the one that yields no bank run as outcome. All others are no PBE.

Suppose that some impatient depositor is prescribed to wait on the equilibrium path. Then, there is a type vector in which some depositor has a profitable deviation. Suppose that depositor 1 is impatient and is asked to wait. Then, she gets a utility of 0 if she waits and $c_{1}^{*}$ if she withdraws. Thus, she is strictly better off to withdraw and this deviation is profitable. Therefore, any equilibrium candidate strategy profile in which some impatient depositor is asked to wait is no PBE since there is a type vector for which some depositor has a profitable deviation. 
Hence, a separating equilibrium candidate is left in which patient depositors wait and impatient ones withdraw on the equilibrium path; a pooling equilibrium candidate in which all depositors withdraw on the equilibrium path; and any other equilibrium candidate in which, on the equilibrium path, all impatient depositors and at least one patient depositor withdraw and at least one patient depositor is asked to wait.

\section{No PBE}

We show next that any pooling equilibrium candidate and any other equilibrium candidate are no PBE.

Pooling equilibrium candidate: On the equilibrium path, any depositor is asked to withdraw, and thus, her type is not revealed. In order to show that this strategy profile is no PBE, we propose a type vector and a history such that some depositor has a profitable deviation.

Before proposing a type vector, we derive the patient depositors' optimal off-equilibrium path strategy depending on their position in the queue. Consider first a patient depositor towards the end of the queue who observes $p-1$ waitings, one of them being depositor 1 . She concludes that she is off-equilibrium, that the $p-1$ depositors that waited before her are patient and that she is the last patient depositor in the queue since she anticipates that all other patient depositors before her upon observing this history apply an analogous reasoning, as will become clear shortly. She believes that all remaining depositors in the queue are impatient and is strictly better off to wait given her type and the observed history (independently of her belief). Waiting yields her $c_{2}^{*}$, while she gets $c_{1}^{*}$ if she withdraws. She waits as prescribed or has a profitable deviation to wait if she is asked to withdraw.

An analogous argument applies to any patient depositor $i$ who observes that depositor 1 waited and in total $\bar{\eta}$ or more waitings, where $\bar{\eta}$ is as derived

in Lemma 1. She has a strictly dominant strategy to wait since $c_{2, i}>c_{1, i}^{*}$ and concludes that those depositors before her that waited are patient and all others impatient. Given that depositor 1 deviated and waited, $i$ concludes 
that depositor 1 is patient and that any subsequent patient depositor upon observing this history applies an identical reasoning and waits as well, anticipating that all other patient depositors reason identically. Her updated belief assigns an equal probability to each type vector in which the remaining patient and impatient depositors occupy the remaining positions behind her in the queue. By sequential rationality she anticipates that all remaining patient depositors will wait upon observing this history. Her strategy is sequentially rational given the observed history and given her belief, and her belief is consistent with her strategy.

Consider now a patient depositor who observed that depositor 1 and in total $\bar{\eta}-1$ depositors waited. She believes that upon observing depositor 1 waiting, any subsequent patient depositor waited and any impatient one withdrew and that the remaining patient and impatient depositors are behind her in the queue. If she waits, then the next patient depositor in the queue has a strictly dominant strategy to wait. Hence, it is sequentially rational for her to wait since this yields her a higher expected payoff given her belief that any depositor before her who withdrew must be impatient, and thus, that there are enough patient depositors left behind her in the queue for period-2 consumption to be strictly larger than period-1 consumption since, by sequential rationality, she anticipates that all of them apply an analogous reasoning and will wait upon observing this history. On this off-equilibrium path, she either deviates profitably by waiting or is prescribed to wait.

Consider now a patient depositor towards the beginning of the queue. Suppose that she observes that depositor 1 waited instead of withdrawing as prescribed. Then, she knows that this depositor deviated bringing the game onto an off-equilibrium path, and concludes that all other depositors before her that waited are patient since an impatient one would never wait and since all patient ones apply an identical reasoning. Her belief assigns an equal probability for all remaining patient depositors to occupy the remaining positions behind her in the queue. By sequential rationality and as 
just derived, she anticipates that all of them will wait upon observing this history since this yields them a strictly larger payoff. Then, her expected payoff from waiting is strictly larger than her payoff from withdrawing. She deviates profitably if she is asked to withdraw and otherwise complies with her strategy and waits.

Going backwards, by induction, this argument applies analogously to all patient depositors in the queue. Given a type vector in which the first depositor is patient, by sequential rationality, she anticipates that if she waits, then she leads the game onto an off-equilibrium path on which it is then sequentially rational for all remaining patient depositors in the queue to wait as well. This yields no bank run as outcome. She has a profitable deviation to wait rather than to withdraw as prescribed. In this case, depositor 2's belief updating is unconstrained since this history has a 0 -probability to occur. However, it is consistent for her to believe that depositor 1 is patient. Based on this, all other depositors then update their beliefs in a Bayesian way.

Thus, we have shown that there are type vectors in which a patient depositor who is first in the line has a profitable deviation to wait rather than to withdraw. Therefore, the pooling strategy profile is no PBE.

Any other equilibrium candidate: In this case, at least one and at most $p-1$ patient depositors and all impatient depositors are asked to withdraw.

Suppose first that $\bar{\eta}$ or more patient depositors are asked to wait such that $c_{2, i}>c_{1}^{*}$ for any patient depositor $i$ who waits. Then, obviously, any patient depositor $i$ who is asked to withdraw has a profitable deviation to wait as well since $c_{2, i}>c_{1}^{*}$; waiting is a strictly dominant strategy for her.

Suppose next that the number of patient depositors who are asked to wait is below $\bar{\eta}$ such that $c_{2, i}<c_{1}^{*}$ for any patient depositor $i$ who waits. As before, the type of a depositor who withdraws is not revealed, though it is consistent for a depositor to believe that those who wait are patient.

As before, there are type vectors in which a patient depositor is first in the queue and is asked to withdraw. However, she has a profitable deviation to 
wait, and by doing this, leads the game down an off-equilibrium path whose outcome is no bank run since then, by sequential rationality, all patient depositors are better off to wait. The proof is analogous to the one for the pooling equilibrium candidate. Therefore, any strategy profile in this class is no PBE either.

\section{PBE}

Up to now we have shown that any strategy profile that yields a bank run is no PBE. We show next that the separating equilibrium candidate predicting no bank run as outcome is a PBE. In order to do this, first the corresponding strategy profile and a possible belief system are described. Then, it is shown that no player's deviation is profitable which establishes existence of PBE.

On the equilibrium path, any patient depositor waits and any impatient one withdraws. In fact, an impatient depositor is asked to withdraw after any history, though she is indifferent to wait or not once the bank ran out of funds. On the same off-equilibrium paths, this indifference holds analogously for patient depositors. Therefore, there are multiple PBE strategy profile candidates that differ on off-equilibrium paths.

On the equilibrium path, every depositor's strategy perfectly reveals her type and it is consistent for a depositor to believe that those who wait are patient and those who withdraw are impatient. Thus, she believes that the remaining patient and impatient depositors are behind her in the queue. By Bayesian updating, each distribution of remaining depositors is equally likely.

The first depositor who knows to be on an off-equilibrium path has to be an impatient one who observes $N-p$ withdrawals. While a patient depositor who observes $N-p$ withdrawals believes that all remaining depositors in the queue are patient, an impatient one who observes this history knows to be on an off-equilibrium path: given her type, this history has an ex ante 0probability and her belief updating is unconstrained. Hence, there are several possible ways to update beliefs consistently and we propose one of them.

Suppose that she believes that all observed withdrawals are due to patient 
depositors. If there are more withdrawals than patient depositors, then she believes that the remaining withdrawals were made by impatient depositors. This is the stringest condition that fosters bank runs. In any case, she anticipates that all depositors behind her are impatient. Finally, if there were less withdrawals than patient depositors, then she believes that all withdrawals are due to patient depositors, and that all impatient and the remaining patient depositors are behind her in the queue.

Consider the first patient depositor $i$ in the queue after this transition to the off-equilibrium path. She updates her belief in a Bayesian way. If $i$ believes that the number of withdrawals due to patient depositors is such that $c_{2, i}<c_{1, i}$, even if $i$ keeps the money in the bank, then $i$ is prescribed to withdraw. If on the other hand $i$ believes that there are enough patient depositors behind her such that $c_{2, i}>c_{1, i}$, provided that $i$ and all those depositors wait, then $i$ is asked to wait.

In the last case, there could be another patient depositor $j \neq i$, at a later position in the queue who observed enough additional withdrawals such that $c_{2, j}<c_{1, j}$, provided that $j$ believes that all withdrawals were due to patient depositors. Then, there is a transition from the off-equilibrium path on which $c_{2, i}>c_{1, i}$ to the one on which $c_{2, j}<c_{1, j}{ }^{16}$ and $j$ is prescribed to withdraw.

Belief updating in this transition from one off-equilibrium path to the other is unconstrained since the observed history has an ex ante 0-probability, and a patient depositor believes that enough if not all other patient depositors were before her in the queue and withdrew, and thus, she anticipates that all remaining depositors behind her in the queue will withdraw as well.

Finally, there is a third but less important type of off-equilibrium path: if the bank ran out of funds, then any subsequent depositor in the queue is indifferent to wait or not independently of her type and belief since her utility

\footnotetext{
${ }^{16}$ Lemma 1 describes all cases in which $c_{2, j}<c_{1, j}$ since on any off-equilibrium path, given the proposed belief system, the condition derived in the proof of Proposition 1 never applies: that is, there cannot be $y$ of funds left and a patient depositor believes that there are only patient depositors behind her in the queue.
} 
is 0 whether she waits or withdraws. In this case, trivially there are several belief systems that are consistent with the strategy profile of the remaining depositors, and any strategy is sequentially rational given any of these beliefs.

\section{No profitable deviation}

We show next that no depositor has a profitable deviation from this strategy profile. Obviously, no impatient depositor can deviate profitably.

Consider next any patient depositor and the different possible histories: on the equilibrium path, no patient depositor $i$ can deviate profitably by withdrawing. Her belief to be on the equilibrium path is consistent with the strategy profile and the available information. Given her belief, it is sequentially rational for $i$ to wait (since $c_{2}^{*}>c_{1}^{*}$ ) and her expected utility weighted by her belief is $u_{i}\left(\left(\theta_{i}-1\right) c_{2}^{*}\right)>u_{i}\left(c_{1}^{*}\right)$ given that $\theta_{i}=2$.

Consider now the different off-equilibrium paths. Suppose that $c_{2, i}>c_{1, i}$ for a patient depositor $i$, even if $i$ believes that all withdrawals were due to patient depositors. Then, given her belief, it is sequentially rational for $i$ to wait and this is consistent with her belief $-i$ believes that there are enough patient depositors behind her in the queue for $c_{2, i}>c_{1, i}$ to hold, provided that all of them wait. Her deviation to withdraw is not profitable.

On any other off-equilibrium path, a patient depositor $i$ believes that enough withdrawals were due to patient depositors such that $c_{2, i}<c_{1, i}$. Hence, it is sequentially rational for $i$ to withdraw and her belief is consistent with her strategy. Her deviation to wait is not profitable since her expected payoff weighted by her belief would yield her less if she waits. All subsequent depositors observe a series of withdrawals, but not the depositors' types, and thus, each's belief is consistent with her strategy and the observed history.

Finally, and as mentioned above, on an off-equilibrium path on which the bank went bankrupt, no depositor's deviation is profitable and any remaining depositor's utility is 0 independently of her strategy, type and belief.

Therefore, we found a strategy profile such that no depositor's deviation is ever profitable given any realization of the type vector and any history. 
This establishes existence and concludes the proof that no bank run is a PBE outcome. Note again that there are other off-equilibrium path belief systems and strategies. Any such strategy profile and belief system that is sequentially rational and consistent, respectively, is also a PBE. Hence, there is no unique PBE strategy profile and belief system.

\section{A unique PBE outcome}

After completely describing all possible strategy profiles that can be constructed given the set of depositors, their types and available strategy choices (wait and withdraw), we proved that any other type of candidate is no PBE, except for the separating equilibrium candidate in which on the equilibrium path patient depositors wait and impatient ones withdraw, and therefore, no bank run occurs. Since this is the only outcome arising from a PBE, it follows that the unique equilibrium outcome is no bank run. 